\title{
3D Printing of Metals
}

\author{
Manoj Gupta \\ Department of Mechanical Engineering, National University of Singapore, 9 Engineering Drive 1, \\ Singapore 117576, Singapore; mpegm@nus.edu.sg; Tel.: +65-6516-6358 \\ Academic Editor: Hugo F. Lopez \\ Received: 26 September 2017; Accepted: 28 September 2017; Published: 29 September 2017
}

3D printing is an emerging technique of immense engineering importance, capable of transforming the way we make components. It has been explored worldwide for metals, ceramics and polymers. $3 \mathrm{D}$ printing offers several advantages such as the following [1,2]:

(a) Shorter lead time

(b) Low cost

(c) Small volume of parts without the need of tooling or fixture

(d) Capability to fabricate near net shapes

(e) Design freedom that allows the fabrication of simple and complex shapes

(f) Potential to handle conventional and specialized materials.

The potential benefits that could be derived if the science and technology of 3D printing were to be established have been the crux behind monumental efforts by governments, in most countries, that invest billions of dollars to develop this manufacturing technology. Multiple engineering sectors are targeting the integration of 3D printing in their manufacturing section, especially where the batch size is not big and the parts are specialized. These requirements are particularly applicable to automotive [2], aerospace [3,4] and biomedical sectors [5,6].

The current Special Issue was targeted at metal-based materials as 3D printing of metals is particularly challenging due to a host of microstructural changes that are encountered, especially when the metals and alloys are exposed to high temperatures. Control of the dimensional accuracy and end properties is still being explored by researchers for different types of metals and alloys as the results of one compositional system cannot be translated to another compositional system. Overall, nine papers (one review and eight research papers) have been published in this issue. The materials investigated were the following:
a. Aluminum-based materials
b. Magnesium-based materials
c. Steels
d. Titanium-based materials
e. Oxide dispersion-strengthened aluminum-based composites

This suggests that there is no preferred metal system that is targeted by researchers but all important metallic materials are equally targeted.

$3 \mathrm{D}$ printing techniques that were utilized in the papers published in this issue included the following:
a. Micro-coating metal additive manufacturing (MCMAM)—new technique
b. Electron beam melting
c. Selective laser melting
d. Laser metal deposition 
Most of the papers, including the review paper, targeted selective laser melting, suggesting its popularity among researchers. The research issues addressed in these papers included the following:

a. Sheet metal forming

b. Effect of heat treatment

c. Failure under compression

d. Porosity distribution, microstructure and hardness

e. Forming defects as a function of processing parameters

f. Wear properties

g. Interrelation between structure size, mechanical characteristics and process defect

h. Interrelation between aging behavior and mechanical performance.

The above indicated research issues broadly indicate that researchers are in the process of tailoring their processing parameters to control the microstructure, including process defects, so that their targeted properties are not compromised and remain suitable for their targeted applications.

Targeted industrial sectors mentioned in these papers included the following:
a. Aerospace sector
b. Biomedical sector
c. Defense
d. Automobile

This suggests the main drivers of 3D printing in the research community. The present Special Issue, in general, is very informative as the nine articles cover a variety of topics and challenges and for different metallic materials (ferrous and non-ferrous) covering four different types of 3D printing techniques and issues related to microstructure, process defects, mechanical properties and heat treatments for a wide spectrum of applications.

Finally, I would like to thank all the authors for their excellent contribution to this issue, to the reviewers for making useful comments and to the Metals editorial staff for their timely publication of these articles.

Conflicts of Interest: The author declares no conflict of interest.

\section{References}

1. ASTM. Standard Terminology for Additive Manufacturing Technologies; F2792-12a; ASTM International: West Conshohocken, PA, USA, 2015.

2. Guo, N.; Leu, M. Additive manufacturing: Technology, applications and research needs. Front. Mech. Eng. 2013, 8, 215-243. [CrossRef]

3. Nickels, L. AM and aerospace: An ideal combination. Met. Powder Rep. 2015, 70, 300-303. [CrossRef]

4. Schiller, G.J. Additive manufacturing for Aerospace. In Proceedings of the IEEE Aerospace Conference, Big Sky, MT, USA, 7-14 March 2015.

5. Bose, S.; Vahabzadeh, S.; Bandyopadhyay, A. Bone tissue engineering using 3D printing. Mater. Today 2013, 16, 496-504. [CrossRef]

6. Ho, C.M.B.; Ng, S.H.; Yoon, Y.-J. A review on 3D printed bioimplants. Int. J. Precis. Eng. Manuf. 2015, 16, 1035-1046. [CrossRef]

(c) 2017 by the author. Licensee MDPI, Basel, Switzerland. This article is an open access article distributed under the terms and conditions of the Creative Commons Attribution (CC BY) license (http://creativecommons.org/licenses/by/4.0/). 